\title{
Avaliação da qualidade do serviço de abastecimento de água em Campina Grande-PB com o uso de indicadores, incluindo o de satisfação dos usuários
}

\section{Evaluation of the quality of the water supply service in Campina Grande-PB with the use of indicators, including user satisfaction $11 / 07 / 2018$ \\ Data de aprovação: $26 / 12 / 2018$}

Data de entrada:

Luísa Eduarda Lucena de Medeiros ${ }^{1 *}$ | Andrea Carla Lima Rodrigues ${ }^{1}$ | Dayse Luna Barbosa ${ }^{1}$ | Patrícia Hermínio Cunha Feitosa' | Mônica de Amorim Coura'

DOI: https://doi.org/10.36659/dae.2020.045

ORCID ID

Medeiros LEL (D) https://orcid.org/0000-0002-9792-1273

Rodrigues ACL (D) https://orcid.org/0000-0002-4764-0430
Barbosa DL (D https://orcid.org/0000-0002-3209-270X

Feitosa PHC (D) https://orcid.org/0000-0001-6937-0817

Coura MA (iD https://orcid.org/0000-0001-5820-9315

\section{Resumo}

Entre os desafios enfrentados pelas concessionárias responsáveis pelo abastecimento de água nos centros urbanos está a prestação de um serviço de qualidade que atenda às exigências dos usuários. Objetivando colaborar com a melhoria do serviço de abastecimento oferecido à população, o presente trabalho propôs o desenvolvimento de um índice de desempenho do serviço de abastecimento de água na cidade de Campina Grande - Paraíba (IDSA-CG). Foram estudados 22 indicadores divididos em cinco categorias: operacional, econômico-financeira, qualidade, infraestrutura e recursos humanos. Dentre os indicadores selecionados está o de satisfação do usuário, criado, neste trabalho, a partir do levantamento da percepção da população a respeito do serviço oferecido pela concessionária e incorporado aos demais indicadores para compor, o mais fielmente possível, o IDSA-CG. Os resultados dos indicadores mostraram que a infraestrutura e a qualidade da água obtiveram valores ótimos, próximos ou iguais aos limites de referência definidos na pesquisa. As maiores deficiências do serviço foram associadas aos indicadores operacionais, apontando para uma necessidade de melhoria das perdas na distribuição, macromedição, e consumo médio de água e energia, e os indicadores econômico-financeiros, que alertam para maior fiscalização das ligações clandestinas de água e monitoramento da inadimplência dos usuários. $O$ indicador de satisfação obteve um valor de $45,44 \%$, que mostrou um usuário pouco satisfeito com o serviço oferecido pela empresa. O resultado do IDSA-CG revelou que o serviço atualmente disponibilizado à cidade é classificado como REGULAR, sendo necessárias medidas estruturantes e administrativas para a melhoria da gestão do mesmo.

Palavras-chave: Gestão de serviços. Indicadores e índice de desempenho. Percepção social.

\section{Abstract}

One of the challenges faced by the water utilities in the urban areas is to provide a quality service and meet user requirements. In order to cooperate in an improvement in the supply service offered to the population, this study suggests the development of a performance index for the water supply service in the city of Campina Grande - Paraiba

\footnotetext{
${ }^{1}$ Universidade Federal de Campina Grande (UFCG) - Campina Grande - Paraíba - Brasil.

* Autora correspondente: lu.mdeirosagmail.com.
} 
(IDSA-CG). To achieve this, 22 indicators were studied and divided into five categories: operational, economic/financial, quality, infrastructural and human resources. Among the selected indicators to this study, there is one called user's satisfaction, which was created based on a survey, to know the population's perspective about the service provided by the water utility and, thus, being incorporated to the other indicators in order to form, as faithfully as possible, the IDSA-CG. The results the indicators showed that the infrastructural indicators and the water quality indicator obtained optimum values, close or equal the reference limits defined in the research. The main service drawbacks are associated to the operational indicators, with a need to improve in the losses in the distribution, macro measurement, average water and energy consumption, and also to the economic/financial indicators, with a more efficient demand to trace clandestine water connections and to monitor the users in debt. The satisfaction indicator obtained a result of 45,44\%, which means that the user is little satisfied with the service offered by the water utility in the city. Finally, the result of the IDSA-CG revealed that the service currently available to the city of Campina Grande can be classified as REGULAR, with the need to introduce structural and administrative measures in order to perform a better system management. Keywords: Management of water supply services. Performance index and indicators. Social perception.

\section{INTRODUÇãO}

O rápido crescimento demográfico e a expansão desordenada dos centros urbanos ocorridos nas últimas décadas têm dificultado o alcance da população aos serviços de saneamento básico. A Lei $n^{\circ}$ 11.445/2007, que estabelece diretrizes nacionais para o saneamento básico no Brasil, tem como princípio fundamental a universalização do acesso aos serviços de abastecimento de água, esgotamento sanitário, limpeza urbana e manejo de resíduos sólidos em todas as áreas urbanas. Essa universalização do saneamento básico não se refere apenas à cobertura, mas também à qualidade do serviço oferecido.

O Instituto Regulador de Água e Resíduos (IRAR, 2007) afirma que a evolução dos serviços de saneamento básico em busca da universalização geralmente é marcada por três fases distintas: (i) Fase da quantidade, em que a prioridade é implantar e ampliar as infraestruturas do sistema e, consequentemente, aumentar a cobertura dos serviços de saneamento no país; (ii) Fase da qualidade, em que as preocupações concentram-se na qualidade dos resíduos lançados no meio receptor; e (iii) Fase da excelência, em que os esforços são destinados à melhoria da qualidade dos serviços prestados aos usuários, na sustentabilidade das prestadoras de serviço e na sustentabilidade ambiental.

Segundo estudo divulgado pelo Instituto Trata Brasil (2014), apesar de ser a sétima economia do mundo, o Brasil ocupava, em 2011, a $112^{a}$ posição em um conjunto de 200 países no quesito saneamento básico. De acordo com esse trabalho, o Índice de Desenvolvimento do Saneamento atingiu 0,581, indicador que está abaixo não só do apurado em países ricos da América do Norte, Europa e Ásia, como também de algumas nações do Norte da África, do Oriente Médio e da América Latina em que a renda média é inferior ao da população brasileira. Entre eles estão o Equador $(0,707)$; o Chile $(0,686)$ e a Argentina $(0,667)$. No que diz respeito ao saneamento básico, o Brasil ainda possui como meta principal atender o máximo possível de usuários. No entanto, além da quantidade, também é preciso atingir níveis na qualidade do recurso oferecido e lançado no meio e dos serviços prestados, sendo este conjunto o verdadeiro indicativo para uma gestão eficiente.

O desenvolvimento de índices para caracterizar os serviços de saneamento básico e auxiliar na 
gestão dos mesmos vem ganhando grande aceitabilidade na área ambiental e de saneamento básico no Brasil e no mundo, especialmente nos centros urbanos, onde o atendimento dos serviços de saneamento é muito variável devido à dinâmica das cidades.

\section{1 Îndices e Indicadores de desempenho}

Um índice de desempenho de serviço (IDS) é uma ferramenta capaz de representar fielmente a realidade de determinado estudo de caso. Entretanto, para o desenvolvimento de um índice, é necessária a agregação de vários dados, podendo ser mensurados a partir de indicadores que levam em consideração aspectos operacionais, estruturais, econômico-financeiros, sociais, ambientais, entre outros.

A Agenda 21 Global ressalta a importância do uso de indicadores e índices na tomada de decisão dos gestores na busca do desenvolvimento sustentável e eficiente (ABAR, 2008).

Os indicadores traduzem, de forma analítica, aspectos mais relevantes. Cada indicador contribui para a quantificação do desempenho sob um dado ponto de vista, numa determinada área, durante um período de tempo. Estes devem apresentar informações de uma realidade, e devem ser avaliados em conjunto e associados ao contexto em que estão inseridos, de forma a evitar erros de interpretação (LOPES, et al., 2016).

Von Sperling (2010) desenvolveu uma pesquisa que realizou uma extensa avaliação de diferentes bases de dados e obteve uma seleção consistente de indicadores para avaliar o serviço de esgotamento sanitário.

No âmbito do abastecimento de água, Heller (2012) realizou um trabalho onde foram avaliadas diferentes modalidades de prestação do serviço de água a partir de uma base de indicadores de abastecimento consagrados na literatura com relação aos aspectos operacionais e gerenciais dos serviços prestados em diversas regiões do país.

Costa et al. (2013) selecionaram seis indicadores baseados no SNIS para avaliação da prestação dos serviços de água e esgoto no âmbito do estado de Minas Gerais. Para tal, consideraram parâmetros de referência para cada um dos indicadores e obtiveram resultados satisfatórios para os indicadores de atendimento e qualidade da água oferecida para todo o Estado.

Marinho e Nascimento (2014) realizaram uma avaliação do saneamento urbano de Macapá a partir de indicadores obtendo bons resultados, com valores superiores às metas esperadas pelas companhias, para os seis indicadores de abastecimento utilizados.

Na linha de pesquisa de índices, Ogata (2014) desenvolveu um Índice de Pobreza Hídrica (IPH) considerando cinco componentes (recurso, acesso, capacidade, uso e meio ambiente) no âmbito da Bacia Hidrográfica do Rio Paraíba. As conclusões da pesquisa resultaram em um IPH classificado como moderado para toda a extensão da Bacia.

Lopes et al. (2016) realizaram uma pesquisa para determinar um índice avaliativo do esgotamento sanitário a partir da seleção de nove indicadores na cidade de Campina Grande-PB e obteve uma classificação final regular para o serviço.

No entanto, a despeito da vasta bibliografia sobre o tema, percebe-se que ainda são poucos os trabalhos que levam em consideração a opinião dos usuários na análise de eficiência dos serviços. A eficiência com a qual determinado serviço é prestado pode ser avaliada por meio da consulta à população que o utiliza cotidianamente para realizar suas atividades. Essa é uma alternativa que vem crescendo no Brasil e no mundo, contemplando uma análise multiavaliativa dos diversos componentes a partir da visão não 
somente da concessionária responsável pelo serviço, mas também dos usuários diretos, que conhecem a dinâmica real dos sistemas de saneamento na prática.

\subsection{Indicadores de recursos humanos na composição de IDS}

O controle social ou participação da comunidade é um dos princípios fundamentais previstos na Lei n 11.445/2007 para embasar a prestação de serviços públicos de saneamento básico. Segundo PAULINS (2005), a satisfação dos usuários está relacionada às expectativas que estes desenvolvem com relação à qualidade dos serviços que estão sendo oferecidos.

As medições da qualidade se concentram em indicadores objetivos e palpáveis, porém, muitas vezes tais indicadores não são aplicáveis para avaliar as peculiaridades dos serviços. Nos últimos anos, tem crescido a utilização de medições mais subjetivas para quantificar indicadores de qualidade. Segundo (HAYES, 2001), essas medições incluem os questionários de satisfação do cliente e enfocam percepções, em complemento aos critérios mais concretos e objetivos, fornecendo um conhecimento mais abrangente das opiniões dos clientes.

Nascimento et. al (2013) identificou a percepção dos usuários quanto à qualidade do sistema de abastecimento de água na cidade de Campina Grande-PB. Para tal, foram aplicados questioná- rios à comunidade, abordando aspectos de qualidade da água e periodicidade de abastecimento. Os resultados mostraram que a maioria dos entrevistados considerou a água de boa qualidade e a frequência de interrupção baixa.

Gonçalves et al. (2015) utilizaram a aplicação de questionários para diagnosticar o serviço de abastecimento de água em Barcarena - Pará. Concluíram que $66 \%$ dos entrevistados não tinham acesso ou não utilizavam tal serviço público, sendo feito uso de poços individuais. A pesquisa revelou ainda que a deficiência na qualidade da água (90\%) seria um dos motivos pela busca de fontes alternativas.

Nesse contexto, o presente trabalho desenvolveu um índice de desempenho do serviço de abastecimento de água para a cidade de Campina Grande - Paraíba (IDSA-CG), com base em indicadores operacionais, econômico-financeiros, de qualidade, infraestruturais e de recursos humanos para auxílio à gestão do serviço no âmbito urbano.

\section{METODOLOGIA}

Para o estudo de indicadores e o desenvolvimento do IDSA - CG foi utilizada uma metodologia composta por quatro etapas: (1) caracterização da área de estudo; (2) seleção de indicadores; (3) coleta de dados e; (4) desenvolvimento do índice. Na Fig. 1 é apresentado o diagrama estruturado das etapas metodológicas da pesquisa. 
Figura 1 - Diagrama estruturado das etapas metodológicas.

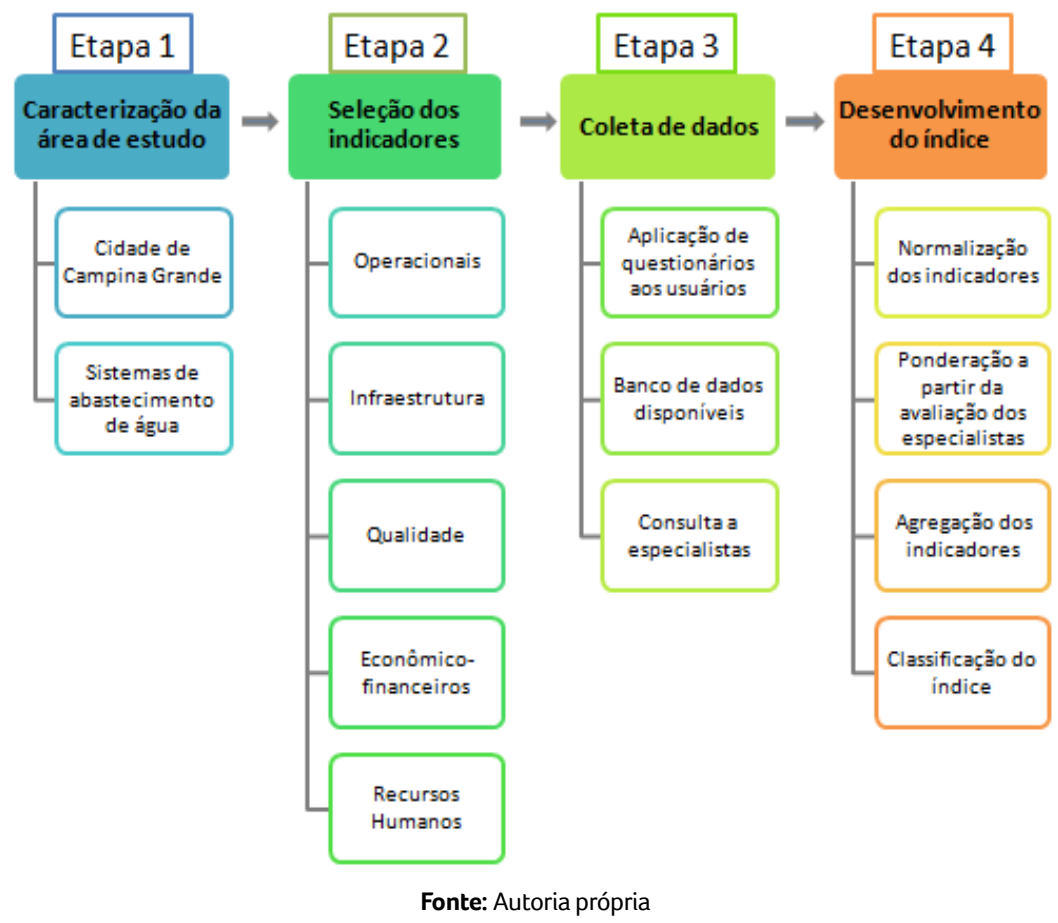

\subsection{Caracterização da área de estudo e do} sistema de abastecimento de água

O município de Campina Grande é o maior do interior da Paraíba e do Nordeste, estando localizado a uma distância de $120 \mathrm{~km}$ da capital do Estado, a 7¹3'32" de latitude Sul e a $35^{\circ} 52^{\prime} 38^{\prime \prime}$ de longitude Oeste. Possui uma área aproximada de $594,182 \mathrm{~km}^{2}$, com população total de 385.213 habitantes, sendo $95 \%$ residentes na zona urbana e $5 \%$ na área rural. A cidade está dividida territorialmente em 50 bairros, com grande diversidade no tocante a área, relevo, densidade populacional e nível socioeconômico.

O serviço de abastecimento de água de Campina Grande é de responsabilidade da Companhia de Água e Esgoto da Paraíba - CAGEPA. O sistema dispõe de uma estação elevatória de água bruta, uma estação de tratamento de água, duas estações elevatórias de água tratada, além de 29 reservatórios espalhados pela cidade e a rede de distribuição.
O manancial responsável pelo abastecimento do sistema é o açude Epitácio Pessoa, localizado na região semiárida do estado, a aproximadamente 42 km de Campina Grande. Este é o principal reservatório da Bacia Hidrográfica do Rio Paraíba com capacidade atual de 411.686.287 $\mathrm{m}^{3}$ e vazão regularizável de $1,23 \mathrm{~m}^{3} / \mathrm{s}$ (PERH, 2006). Seu gerenciamento está sob a responsabilidade do Departamento Nacional de Obras contra a Seca - DNOCS.

Os períodos de escassez hídrica observados nos últimos anos, associados aos elevados índices de evaporação da região e à gestão inadequada, ocasionaram uma redução considerável do volume acumulado no reservatório Epitácio Pessoa e, consequentemente, da disponibilidade de água para população do município de Campina Grande. Em abril de 2017, o manancial atingiu índices volumétricos mínimos, chegando a operar com volume "morto" (22,25 milhões de $\left.\mathrm{m}^{3}\right)$ apenas para abastecimento (DNOCS, 2017). Atualmente, 
após período chuvoso e com o aporte das águas advindas da transposição do Rio São Francisco, o açude encontra-se com aproximadamente $30 \%$ de sua capacidade (AESA, 2018).

Após captada, a água é encaminhada para uma estação de tratamento de água (ETA), onde é tratada e recalcada através de duas elevatórias e destinando-se a dois reservatórios, denominados de R-09 e R-05, localizados em Campina Grande (SILVA et. al, 2015).

A cidade apresenta relevo acidentado, e a rede de distribuição de água foi projetada para atender a quatro zonas de pressão distintas. Duas zonas são atendidas por meio do reservatório R-09, e outras duas pelo reservatório R-05. O material da tubulação da rede de distribuição é de cimento amianto e ferro fundido, nos trechos antigos e PVC nos mais recentes.

O sistema de abastecimento de Campina Grande possui 125.173 ligações ativas de água, sendo 124.167 micromedidas com um volume médio consumido de 15,4 milhões de $\mathrm{m}^{3}$ por ano (SNIS, 2015). De acordo com o ranking do Instituto Trata Brasil (2017) (dados referentes ao SNIS-2015), a cidade ocupa a $4^{\mathrm{a}}$ posição em relação aos indicadores de água.

\subsection{Seleção dos indicadores}

Devido a limitações dos dados disponíveis, não foi possível realizar a escolha de indicadores a partir de um processo amplo com a participação de diferentes agentes da sociedade. Optou-se, então, por um processo seletivo mais simplificado, entretanto cuidadosamente estudado, de modo a garantir a confiabilidade dos resultados obtidos. Assim, a escolha dos indicadores foi feita a partir da disponibilidade de dados primários e da análise de um conjunto de indicadores nacionais e internacionais referentes aos serviços de abastecimento de água, bem como indicadores já consagrados nas literaturas nacional e internacional. Aspectos como a opinião de especialistas, a coerência com as características do sistema de abastecimento de água da cidade, a frequência em outros estudos e a confiabilidade da fonte também foram levados em consideração para essa escolha.

Na Fig. 2 estão listados os indicadores selecionados para o desenvolvimento do trabalho e agrupados em cinco categorias (operacionais, econômico-financeiros, de qualidade, infraestrutura e recursos humanos) pré-estabelecidas para compor, de forma mais representativa, o índice final.

Figura 2 - Indicadores selecionados para a pesquisa

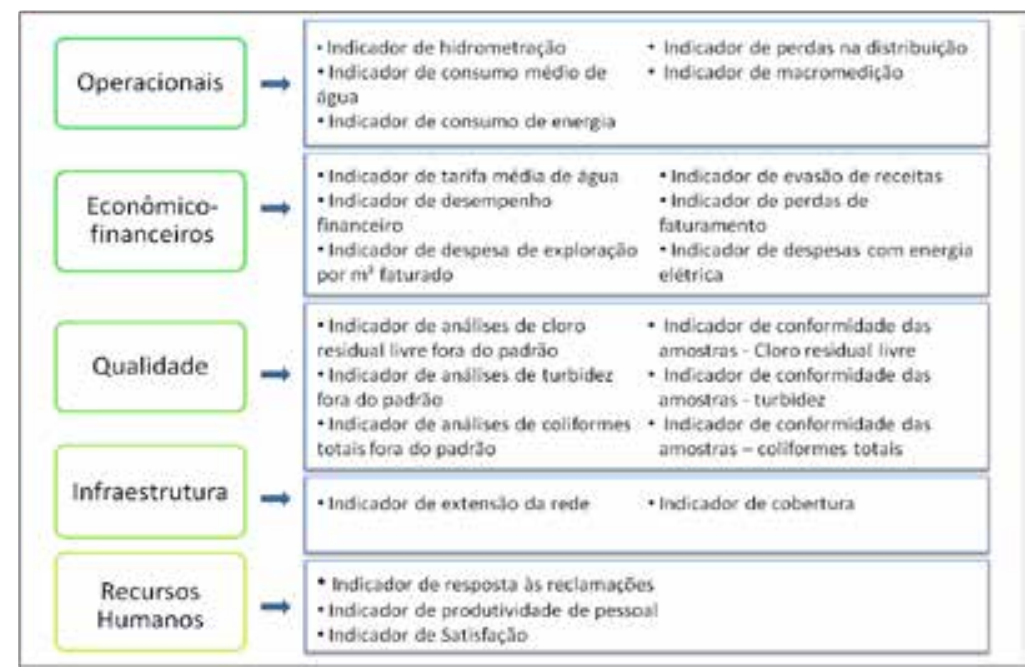

Fonte: Autoria própria 
A maioria dos indicadores escolhidos foi sugerida por entidades consagradas (SNIS, ABAR, IWA). Tendo em vista a ausência de metodologias avaliativas para compor um indicador de satisfação dos usuários foram propostos, nesta pesquisa, níveis de satisfação subdivididos de acordo com as faixas percentuais descritas na Tabela 1. As respostas obtidas nos questionários foram segregadas nas quatro categorias indicadas na Tabela 1.

Tabela 1 - Classificação dos Intervalos de satisfação dos usuários

\begin{tabular}{|c|c|c|c|c|}
$\begin{array}{c}\text { Níveis de } \\
\text { Satisfação }\end{array}$ & $\begin{array}{c}\text { Muito } \\
\text { satisfeito }\end{array}$ & Satisfeito & $\begin{array}{c}\text { Pouco } \\
\text { satisfeito }\end{array}$ & Insatisfeito \\
\hline $\begin{array}{c}\text { Faixa } \\
\text { Percentual }\end{array}$ & $100-76$ & $75-51$ & $51-26$ & $25-0$ \\
\hline \multicolumn{4}{c}{ Fonte: Autoria própria } \\
\hline
\end{tabular}

O valor final do indicador de satisfação foi obtido de acordo com a Eq. 1.

$$
I_{\text {satisfação }}=\sum_{i=1}^{n}\left(R_{i} x C_{\text {médio }(i)}\right) / n
$$

Onde:

$\mathrm{I}_{\text {satisfação }}=$ Indicador final de satisfação dos usuários; $\mathrm{i}$ = perguntas constituintes do indicador;

$\mathrm{n}$ = número total de perguntas da amostra;

$\mathrm{R}_{\mathrm{i}}=$ Percentual de resposta dos entrevistados para cada pergunta;

$\mathrm{C}_{\text {médio(i) }}=$ Valor médio referente à categoria que a resposta está inclusa (0-25\%,26-50\%,51-75\% e 76-100\%).

\subsection{Coleta de dados}

Os dados para a pesquisa foram coletados a partir de informações oficiais disponíveis no Sistema Nacional de Informações em Saneamento - SNIS e no Instituto Brasileiro de Geografia e Estatística IBGE. Os dados obtidos foram relacionados à população, infraestrutura e peculiaridades dos serviços de abastecimento de água, como: operação, qualidade de água e aspectos econômico-financeiros.

Além das informações oficiais obtidas nos bancos de dados, foram aplicados questionários à população residente em todos os bairros da cidade para obter referências quanto à satisfação dos usuários em relação ao serviço de abastecimento de água ofertado. Para o cálculo do tamanho da amostra a ser entrevistada e visando à quantificação dos questionários, utilizou-se a abordagem referente a populações infinitas, conforme a Eq. 2 (LUCHESA, 2011):

$n=\frac{Z^{2} \cdot p \cdot(1-p)}{e^{2}}$

Onde:

$\mathrm{n}=$ parcela da população que será investigada;

e = erro amostral de 5\%;

$p$ = grau de homogeneidade da população estudada;

Z = variável aleatória normal padrão obtida a partir do grau de confiança de $95 \%$.

Considerando uma população atual estimada da cidade de Campina Grande de 389.161 habitantes (PMSB, 2014) e utilizando a Eq. 2, foi obtida uma mostra representativa $n$ igual a 246 usuários para utilização na pesquisa. Com esse valor, foi possível calcular o número de representantes mínimo em cada bairro a partir do percentual de atendimento disponível na plataforma SIDRAIBGE (2010). Os entrevistados escolhidos para responder aos questionários foram usuários residenciais do serviço de abastecimento, homens e mulheres, maiores de 16 anos, alfabetizados e de todas as classes sociais. Esses dados foram utilizados para desenvolver um indicador de satisfação que, somado aos demais indicadores, compuseram o IDSA-CG. 


\subsection{Determinação do índice de desempenho do serviço de água - IDSA_CG}

Para obtenção desse índice, foram realizados os procedimentos de normalização, ponderação, agregação e classificação descritos a seguir.

\subsubsection{Normalização}

A etapa de normalização de indicadores tem como objetivo torná-los adimensionais para posterior agregação destes no processo de formação do índice proposto no trabalho. Para tal, foi utilizada a metodologia de redimensionamento contínuo, na escala de 0 a 1, de acordo com a Eq. 3 (JUWANA; MUTTIL; PEREIRA, 2012).
$S_{i}=\frac{X_{i}-X_{i n f}}{X_{\text {sup }}-X_{\text {inf }}}$

Onde: $\mathrm{Si}$-Valor normalizado;

Xi - Valor a ser normalizado;

Xinf-Limite inferior e

Xsup - Limite superior.

Os limites superiores e inferiores da Eq. 3 foram determinados a partir de órgãos oficiais, trabalhos acadêmicos anteriores ou metas propostas para os serviços de abastecimento de água no Brasil.

Na Tabela 2 são apresentados os limites máximos e mínimos estabelecidos para os indicadores estudados.

Tabela 2 - Normalização dos indicadores

\begin{tabular}{|c|c|c|c|}
\hline INDICADORES OPERACIONAIS & Limite superior & Limite inferior & Fonte \\
\hline $10_{1}$ - Indicador de hidrometração & $100 \%$ & $92,90 \%$ & SNIS 2016 \\
\hline $1 \mathrm{O}_{2}$ - Indicador de consumo médio de água & 50l/hab.dia & 154,1 l/hab.dia & SNIS 2016; OMS 2011 \\
\hline $1 \mathrm{O}_{3}$ - Indicador de consumo de energia & $0 \mathrm{kWh} / \mathrm{m}^{3}$ & $0,43 \mathrm{kWh} / \mathrm{m}^{3}$ & SNIS 2016 \\
\hline $\mathrm{IO}_{4}$ - Indicador de perdas na distribuição & $15 \%$ & $38,1 \%$ & ODEBRECHTA/SNIS 2016 \\
\hline $1 \mathrm{O}_{5}$ - Indicador de macromedição & $76,6 \%$ & $0 \%$ & SNIS 2016 \\
\hline INDICADORES ECONÔMICO-FINANCEIROS & Limite superior & Limite inferior & Fonte \\
\hline $\mathrm{IEF}_{1}$ - Indicador de tarifa média de água & $6,79 \mathrm{R} \$ / \mathrm{m}^{3}$ & $3,36 \mathrm{R} \$ / \mathrm{m}^{3}$ & SNIS 2016 \\
\hline $\mathrm{IEF}_{2}$ - Indicador de desempenho financeiro & $267,07 \%$ & $99,85 \%$ & SNIS 2016 \\
\hline $\mathrm{IEF}_{3}$ - Indicador de despesa de exploração por $\mathrm{m}^{3}$ faturado & $1,74 \mathrm{R} \$ / \mathrm{m}^{3}$ & $3,10 \mathrm{R} \$ / \mathrm{m}^{3}$ & SNIS 2016 \\
\hline $\mathrm{IEF}_{4}$ - Indicador de evasão de receitas & $0 \%$ & $9,62 \%$ & SNIS 2016 \\
\hline $\mathrm{IEF}_{5}$ - Indicador de perdas de faturamento & $0 \%$ & $38,9 \%$ & SANEPAR/SNIS-2016 \\
\hline $\mathrm{IEF}_{6}$ - Indicador de despesas com energia elétrica & $0 \%$ & $14,19 \%$ & CAESB/SNIS-2016 \\
\hline INDICADORES DE QUALIDADE & Limite superior & Limite inferior & Fonte \\
\hline IQ & $0 \%$ & $100 \%$ & Portaria nº 5 (MS-2017) \\
\hline $\mathrm{IQ}_{2}$ - Indicador de Incidência das análises de turbidez fora do padrão & $0 \%$ & $100 \%$ & Portaria nº 5 (MS-2017) \\
\hline $\mathrm{IQ}_{3}$ - Indicador de Incidência das análises de coliformes totais fora do padrão & $0 \%$ & $100 \%$ & Portaria nº 5 (MS-2017) \\
\hline $\mathrm{IQ}_{4}$ - Indicador de conformidade da quantidade de amostras - Cloro residual livre & - & $100 \%$ & Portaria nº 5 (MS-2017) \\
\hline $\mathrm{IQ}_{5}$ - Indicador de conformidade da quantidade de amostras - turbidez & - & $100 \%$ & Portaria nº 5 (MS-2017) \\
\hline $\mathrm{IQ}_{6}$ - Indicador de conformidade da quantidade de amostras - coliformes totais & - & $100 \%$ & Portaria n 5 (MS-2017) \\
\hline INDICADORES INFRAESTRUTURA & Limite superior & Limite inferior & Fonte \\
\hline $\mathrm{IE}_{1}$ - Indicador de extensão da rede & 3,92 m/lig & $12,54 \mathrm{~m} / \mathrm{lig}$ & SNIS 2016 \\
\hline $\mathrm{IE}_{2}$ - Indicador de cobertura da rede & $100 \%$ & $89,83 \%$ & SNIS 2016 \\
\hline INDICADORES DE RECURSOS HUMANOS & Limite superior & Limite inferior & Fonte \\
\hline $\mathrm{IRH}_{1}$ - Indicador de resposta às reclamações & $100 \%$ & $0 \%$ & - \\
\hline $\mathrm{IRH}_{2}$ - Indicador de produtividade pessoal total & 1.895 Lig/emp. & 326,18 Lig/emp. & CAGECE/SNIS-2016 \\
\hline $\mathrm{IRH}_{3}$ - Indicador de satisfação & $100 \%$ & $0 \%$ & - \\
\hline
\end{tabular}

Fonte: Autoria própria 


\subsubsection{Ponderação}

A etapa de ponderação foi obtida a partir da consulta a especialistas das áreas de saneamento e de recursos hídricos e conhecedores da realidade local: professores pesquisadores do curso de Engenharia Civil (UFCG), pesquisadores de recursos hídricos da Agência Reguladora de Água na Paraíba (AESA) e engenheiros da concessionária responsável pelos serviços de abastecimento de água de Campina Grande-PB, a CAGEPA. Cada um dos 22 indicadores escolhidos para a pesquisa foi avaliado pelos especialistas quanto à importância e praticidade com pontuações de 1 a 5 (Tabela 3), segundo a metodologia proposta por Von Sperling (2013). Após a avaliação dos especialistas, os resultados foram tabulados e o peso de cada indicador obtido a partir da soma das médias das respostas quanto aos dois critérios analisados no questionário.

Tabela 3 - Critérios avaliados pelos especialistas

\begin{tabular}{|c|c|c|}
\hline Pontuação & IMPORTÂNCIA & PRATICIDADE \\
\hline 5 & Muito importante & Muito prático \\
\hline 4 & Importante & Prático \\
\hline 3 & Importância moderada & Praticidade moderada \\
\hline 2 & Pouco importante & Pouco prático \\
\hline 1 & Irrelevante & Irrelevante \\
\hline \multicolumn{3}{|c|}{ Fonte: Autoria própria } \\
\hline
\end{tabular}

\subsubsection{Agregação}

Nesta etapa, os indicadores foram agregados para a posterior geração do IDSA-CG. O método escolhido para a agregação foi o aritmético, definido pela Eq. 4.

$I D S A \_C G=\sum_{i=0}^{n} w_{i} x S_{i}$
Onde:

IDSA-CG - Índice de desempenho do serviço de água de Campina Grande;

wi - Peso atribuído ao componente, neste caso o peso de cada indicador;

$\mathrm{Si}$ - O valor atribuído ao componente, neste caso o valor de cada indicador após normalizado;

$\mathrm{n}$ - Número de indicadores utilizados.

\subsubsection{Classificação do IDSA-CG}

A classificação do IDSA-CG foi realizada considerando uma divisão numérica dos valores em cinco intervalos com variação regular. A escolha pela classificação do índice em categorias teve como base estudos anteriores desenvolvidos na área de saneamento, tais como Ogata (2014) e Lopes (2016), que utilizaram classificações semelhantes. Na Tabela 4 são categorizados os intervalos de classificação utilizados na pesquisa.

Tabela 4 - Categorias de classificação nominal do índice de água

\begin{tabular}{|c|c|c|c|c|c|}
\hline \multirow{2}{*}{ Classificação } & \multicolumn{5}{|c|}{ CATEGORIAS } \\
\cline { 2 - 6 } & Ótimo & Bom & Regular & Ruim & Péssimo \\
\hline Pontuação & $10-8$ & $8-6$ & $6-4$ & $4-2$ & $2-0$ \\
\hline
\end{tabular}

Fonte: Adaptado de Ogata (2014), Lopes (2016)

\section{RESULTADOS E DISCUSSÃO}

\subsection{Resultados relacionados aos indicadores}

$\mathrm{Na}$ Tabela 5 são apresentados os resultados obtidos para os 22 indicadores escolhidos na pesquisa. Alguns dos valores mais relevantes foram discutidos. 
Tabela 5 - Resultados obtidos para os indicadores selecionados

\begin{tabular}{|c|c|}
\hline INDICADORES OPERACIONAIS & VALORES OBTIDOS \\
\hline $1 \mathrm{O}_{1}$ - Indicador de hidrometração & $99,19 \%$ \\
\hline $1 \mathrm{O}_{2}$ - Indicador de consumo médio de água & 97,09 l/hab.dia \\
\hline $1 \mathrm{O}_{3}$ - Indicador de consumo de energia & $0,28 \mathrm{kWh} / \mathrm{m}^{3}$ \\
\hline $1 \mathrm{O}_{4}$ - Indicador de perdas na distribuição & $37,1 \%$ \\
\hline $1 \mathrm{O}_{5}-$ Indicador de macromedição & $43,64 \%$ \\
\hline INDICADORES ECONÔMICO-FINANCEIROS & VALORES OBTIDOS \\
\hline $\mathrm{IEF}_{1}$ - Indicador de tarifa média de água & $3,49 \mathrm{R} \$ / \mathrm{m}^{3}$ \\
\hline $\mathrm{IEF}_{2}$ - Indicador de desempenho financeiro & $97,45 \%$ \\
\hline $\mathrm{IEF}_{3}$ - Indicador de despesa de exploração por $\mathrm{m}^{3}$ faturado & $2,49 \mathrm{R} \$ / \mathrm{m}^{3}$ \\
\hline $\mathrm{IEF}_{4}$ - Indicador de evasão de receitas & $13,54 \%$ \\
\hline $\mathrm{IEF}_{5}$ - Indicador de perdas de faturamento & $-6,75 \%$ \\
\hline $\mathrm{IEF}_{6}$ - Indicador de despesas com energia elétrica & $9,28 \%$ \\
\hline INDICADORES DE QUALIDADE & VALORES OBTIDOS \\
\hline IQ - Indicador de Incidência das análises de cloro residual livre fora do padrão & $5,9 \%$ \\
\hline $\mathrm{IQ}_{2}$ - Indicador de Incidência das análises de turbidez fora do padrão & $5,2 \%$ \\
\hline $\mathrm{IQ}_{3}$ - Indicador de Incidência das análises de coliformes totais fora do padrão & $2,2 \%$ \\
\hline $\mathrm{IQ}_{4}$ - Indicador de conformidade da quantidade de amostras - Cloro residual livre & $100 \%$ \\
\hline $\mathrm{IQ}_{5}$ - Indicador de conformidade da quantidade de amostras - turbidez & $100 \%$ \\
\hline $\mathrm{IQ}_{6}$ - Indicador de conformidade da quantidade de amostras - coliformes totais & $100 \%$ \\
\hline INDICADORES INFRAESTRUTURA & VALORES OBTIDOS \\
\hline $\mathrm{IE}_{1}$ - Indicador de extensão da rede & 4,4 m/ligação \\
\hline $\mathrm{IE}_{2}$ - Indicador de cobertura da rede & $99,98 \%$ \\
\hline INDICADORES DE RECURSOS HUMANOS & VALORES OBTIDOS \\
\hline $\mathrm{IRH}_{1}$ - Indicador de resposta às reclamações & $75,76 \%$ \\
\hline $\mathrm{IRH}_{2}$ - Indicador de produtividade pessoal total & 310,48 lig/emp. \\
\hline $\mathrm{IRH}_{3}$ - Indicador de satisfação & $45,44 \%$ \\
\hline
\end{tabular}

Fonte: Autoria própria

$\mathrm{O}$ indicador operacional de hidrometração $\left(1 \mathrm{O}_{1}\right)$ apresentou um resultado de 99,19\%, acima, segundo o SNIS (2016), da média regional $(90,1 \%)$ e da nacional $(92,9 \%)$. A partir desses resultados pode-se concluir que a concessionária responsável pelo serviço faz um controle eficiente das micromedições, ou seja, do volume de água consumido nas ligações da rede.

Para Borges (2007), uma micromedição eficiente, além de constituir um importante dado para se chegar a um confiável índice de perdas, proporciona maior sensibilidade na detecção de vazamentos não visíveis, fornece informações mais precisas para previsão de demandas futuras em sistemas de abastecimento de água, garante uma tarifação mais justa e confiável e induz a comportamentos de conservação dos recursos naturais diminuindo os desperdícios.

Os indicadores operacionais de consumo de água $\left(\mathrm{IO}_{2}\right)$ e energia $\left(\mathrm{IO}_{3}\right)$, perdas na distribuição $\left(\mathrm{IO}_{4}\right) \mathrm{e}$ macromedição $\left(\mathrm{IO}_{5}\right)$ apresentaram avaliação negativa quando comparados aos limites apresentados na Tabela 2.

O elevado consumo de energia $\left(0,28 \mathrm{kWh} / \mathrm{m}^{3}\right)$ tem relação direta com o fato do manancial responsável pelo abastecimento da cidade localizar-se em uma cota topográfica mais baixa, sendo preciso o bombeamento da água tanto no trajeto do açude até a ETA como também desta até os reservatórios de regularização de água na cidade. Outro agravante é que a cidade de Campina Grande possui relevo variável, não sendo possível, em algumas áreas, o abastecimento por gravidade, o que aumenta ainda mais os custos com energia no SAA.

Alguns autores têm estudado a redução dos custos associados à energia elétrica em sistemas de abastecimento. Carvalho (2012) desenvolveu um controlador não-linear, utilizando a técnica de controle inteligente fuzzy, aplicável a redes pres- 
surizadas de distribuição de água visando minimizar o consumo de energia elétrica. Os resultados obtidos indicaram uma economia de energia da ordem de 12,17\%. Moura (2010) identificou ações que podem ser realizadas no âmbito da adoção de sistemas de gestão de energia pelas companhias de saneamento de forma a utilizar melhor os recursos energéticos. Dentre as alternativas possíveis, foi discutida principalmente a alteração do sistema operacional por meio da utilização de inversores de frequência nos conjuntos motor-bomba; concluiu-se que a ação envolve múltiplos fatores além da própria questão técnica. Assim, cada caso deve ser estudado individualmente, ponderadas as diversas alternativas, em função dos recursos disponíveis (físicos e financeiros).

Quanto ao alto índice de perdas $(37,1 \%)$ ao longo da rede de abastecimento, esse pode estar diretamente associado à falta de macromedição (apenas $43,64 \%$ do total do sistema quando se almeja um mínimo de 76,5\%). Tardelli Filho (2015) afirma que por meio da macromedição é possível investigar a possibilidade de furtos de água, submedições ou vazamentos no sistema, e recomenda a medição de vazão na entrada e na saída dos sistemas de abastecimento.

Apesar de elevado se comparado aos sistemas mais eficientes (15\%), o percentual de perdas na distribuição do sistema avaliado ainda figura entre os mais baixos do país. Segundo estudo do Trata Brasil (2017), a CAGEPA é a empresa de saneamento do Nordeste que menos desperdiça água, sendo o valor médio de perdas de $46 \%$ em sistemas de abastecimento na região e $38 \%$ no país. Todavia, grandes avanços ainda precisam ser feitos para que a perda de água no sistema possa atingir os valores desejados.

Do ponto de vista econômico-financeiro, o serviço obteve bons resultados, com exceção dos indicadores de tarifa média de água $\left(\mathrm{IF}_{1}\right)$, evasão de receitas $\left(\mathrm{IF}_{4}\right)$ e despesas com energia elétrica $\left(\mathrm{IF}_{6}\right)$.
A tarifa média de água $\left(3,49 \mathrm{R} \$ / \mathrm{m}^{3}\right)$ avaliada pelo Indicador IEF1 apresentou valor próximo ao limite inferior de 3,36 R $\$ / \mathrm{m}^{3}$ (SNIS, 2016). Quanto maior a receita operacional direta por $\mathrm{m}^{3}$ de água faturada, melhor para a companhia. Para um bom desempenho financeiro do sistema e considerando a necessidade de redução do consumo de água, uma alternativa a ser considerada seria o aumento da tarifa. No entanto, diante das lacunas ainda existentes em relação ao serviço oferecido à população, o aumento da tarifa não parece ser a solução mais adequada. Outras alternativas devem ser avaliadas, tais como o controle de perdas para melhoria do desempenho financeiro e o estímulo a campanhas educativas de conscientização visando à redução do consumo de água.

Com relação à evasão de receitas, essa pode ser controlada com a proposição de um programa de fidelidade aos usuários e descontos nas contas pagas até o vencimento, minimizando a perda de receitas por falta de pagamento, além da fiscalização mais eficiente das ligações clandestinas existentes na rede de distribuição.

$\mathrm{O}$ indicador de despesas com energia elétrica $\left(\mathrm{IF}_{6}\right)$ apresentou o valor de 9,28\% distante do limite desejável (0\%) apontado no SNIS (2016), entretanto justificado pelas características topográficas do SAA, já discutidas durante a avaliação do $1 \mathrm{IO}_{3}$ (Indicador de consumo de energia). Particularmente para o sistema avaliado, sugere-se um estudo de viabilidade econômica da construção de reservatórios intermediários em pontos estratégicos da rede de distribuição de modo a garantir o atendimento majoritário por gravidade, ou a avaliação de alternativas propostas em outros estudos conforme mencionado anteriormente.

Todos os indicadores da categoria qualidade da água $\left(I_{-}, I_{2}, I_{-}, I_{4}, I_{5}\right.$ e IQ $\left.{ }_{6}\right)$ apresentaram resultados dentro do esperado. Tais resultados indicam a conformidade dos parâmetros, cloro residual livre, turbidez e coliformes totais e da 
quantidade de amostras analisadas com os valores estabelecidos na Portaria de Consolidação $\mathrm{n}^{\circ}$ 5/17 do MS (BRASIL, 2017). Considerando os dados apresentados pelo SNIS, pode-se inferir que, em relação a tais parâmetros, a água distribuída na cidade obedece aos requisitos legais. Entretanto, a crise hídrica vivenciada pelo açude Epitácio Pessoa, atualmente trabalhando com $29 \%$ de sua capacidade total, impôs algumas mudanças à rotina da ETA, principalmente em relação ao monitoramento e controle de parâmetros como a concentração de cianotoxinas nas águas afluentes e efluentes à ETA. Indicadores relacionados a este e outros parâmetros não foram avaliados nesta pesquisa devido à ausência de dados. Portanto, apesar dos resultados apresentados pelos indicadores de qualidade ilustrados nesta pesquisa, os mesmos não são suficientes para classificar a água disponibilizada pela concessionária como sendo própria ou não para consumo humano.

Os indicadores de infraestrutura, IE1 e IE2, alusivos à extensão e cobertura da rede, respectivamente, em Campina Grande apresentaram bons resultados quando comparados com a média dos serviços de abastecimento de água no Brasil fornecidos pelo SNIS (2016). Os valores de referência citados na Tabela 2 são metas a serem alcançadas pelas concessionárias e/ou os melhores resultados conseguidos por empresas consideradas excelentes na prestação do serviço no país. Assim sendo, o valor de 4,4 m/ligações obtido para o indicador de extensão de rede está muito abaixo dos 9,2 m/ ligações já considerados satisfatórios para a realidade dos sistemas de abastecimento de água brasileiros. E o valor de $100 \%$ encontrado para o IE2 mostra que toda a população urbana da cidade já possui água encanada. Portanto, em relação à cobertura de rede de distribuição, observa-se que Campina Grande já atinge a universalização exigida no Plano de saneamento básico da cidade PMSB-CG (2015) no ambiente urbano.
Por outro lado, Galvão Junior (2009) alerta que a avaliação da população coberta apenas identifica se o domicílio estava ligado à rede de distribuição de água, não fornecendo informações acerca da qualidade e da continuidade do abastecimento. Portanto, os percentuais apresentados pelos sistemas de informação podem sobrevalorizar quanto às reais condições de universalização.

$\mathrm{O}$ indicador de recursos humanos $\mathrm{IRH}_{1}$, que representa a resposta da concessionária às reclamações da população sobre o serviço oferecido, apresentou um resultado de $62 \%$, ainda distante do valor ideal que é de $100 \%$.

De acordo SNIS (2016), reclamações ou solicitações de serviços correspondem a todas as queixas de clientes e pedidos de serviços dirigidos ao prestador de serviços. Já os serviços executados são quaisquer serviços realizados nos sistemas, decorrentes das reclamações ou solicitações, tais como verificação de falta d'água; conserto de quebramento nas redes, adutoras e ligações prediais; execução de ligações; instalação ou aferição de hidrômetros; vistorias para verificação de vazamentos; e outros de natureza similar.

É esperado que a maioria das reclamações feitas pelos usuários do serviço seja respondida em um curto intervalo de tempo. Para tal, é preciso que a prestadora possua um sistema de comunicação mais efetivo que atualize as informações e reclamações em tempo real, buscando um poder de resposta mais rápido e eficaz. Além disso, a eficiência desse indicador está diretamente ligada ao número de funcionários responsáveis pelo setor de manutenção e reparos da concessionária. Portanto, baixos valores podem apontar para a insuficiência de quadro pessoal.

$\mathrm{O}$ indicador de satisfação $\left(\mathrm{IRH}_{3}\right)$ obteve o valor de $45,44 \%$, evidenciando um usuário pouco satisfeito com a empresa distribuidora de água. A opinião do usuário (receptor final) é um importante termômetro da avaliação da qualidade do serviço, devendo 
ser levada em consideração junto com os outros aspectos. A espacialização das respostas obtidas nos questionários aplicados junto à população e utilizados para compor o indicador de satisfação $\left(\mathrm{IRH}_{3}\right)$ será detalhadamente apresentada a seguir.

\subsection{Resultados referentes à espacialização da satisfação do usuário}

Os resultados referentes à distribuição espacial por bairros da percepção dos usuários em relação ao serviço de abastecimento oferecido em Campina Grande estão apresentados na Fig. 3. Os dados inconclusivos registrados ocorreram devido à falta de consenso entre as informações obtidas, sendo impossível estabelecer uma maioria com opinião representativa.

$\mathrm{Na}$ Fig. 3a é ilustrada a opinião sobre a qualidade da água que chega até as residências na cidade. $A$ resposta obtida reflete que a maioria dos usuários entrevistados, nos diferentes bairros da cidade, não considerou de boa qualidade a água oferecida pela concessionária. Esse resultado contradiz os dados obtidos para os indicadores de qualidade da água $\left(\mathrm{IQ}_{1}, \mathrm{IQ}_{2}, \mathrm{IQ}_{3}, \mathrm{IQ}_{4}\right.$ e $\left.\mathrm{IQ}_{5}\right)$, que apontam uma água dentro dos padrões previstos pela Portaria de Consolidação n ${ }^{\circ}$ 5/2017 do MS, no que diz respeito aos parâmetros de cloro, turbidez e coliformes totais. Acredita-se que uma das justificativas possíveis para esse resultado é o fato de os questionários terem sido aplicados durante um período de racionamento de água. Segundo os entrevistados, a água apresenta uma qualidade inferior à ofertada em períodos normais de abastecimento, estando mais turva, com sabor e/ ou odor. Apesar de a opção "ótima" estar disponível nos questionários de avaliação, nenhum bairro obteve a maioria das respostas nessa categoria.

É interessante destacar que essa redução de qualidade observada pela população poderá estar associada ao uso de reservatórios para armazenamento de água nas residências e à falta de lim- peza periódica desses reservatórios. Nesse caso, a concessionária ficaria isenta da responsabilidade. Ressalta-se também que, apesar da resposta apresentada pelos questionários, a CAGEPA considera a água própria para consumo e embasa sua afirmação por meio de laudos de análises laboratoriais diários da qualidade da água tratada.

A percepção dos usuários quanto à presença de pontos de vazamentos nas redes de distribuição da cidade foi espacializada conforme mostrado na Fig. 3b. A maioria dos usuários entrevistados não observou vazamentos nos bairros onde residem. Exceção pode ser observada em alguns bairros (Ex. José Pinheiro e Palmeira), onde foi registrada frequência de vazamentos diária e semanal, respectivamente. A incidência de vazamentos em tais localidades pode estar associada à antiguidade da rede de distribuição e à ocorrência de elevadas pressões na rede, que podem aumentar a frequência de quebras nas tubulações em pontos específicos. Também durante períodos de racionamento, quando são feitas manobras operacionais para atender a zonas diferentes da rede, as tubulações nas zonas ficam mais susceptíveis a danos, uma vez que a chegada de água com pressão e velocidade elevadas nas canalizações, antes vazias, pode causar desgastes e rompimento do material. Por outro lado, para que a população seja alertada quanto a essa questão, faz-se necessário que o vazamento esteja visível. Logo, o usuário não poderá identificar os microvazamentos na rede.

A percepção dos usuários quanto à eficiência do serviço ofertado é apresentada na Fig. 3c. Percebe-se que os bairros onde os usuários classificam o serviço como ineficiente estão distribuídos espacialmente de forma aleatória na cidade. A relação dessas respostas com o poder aquisitivo da população não é significativa, pois bairros com as mesmas características classificam o serviço de formas diferentes. A maioria dos usuários entrevistados considera que o serviço é realizado de forma parcialmente eficiente. 
Fatores como a ausência de automação no monitoramento da rede, o número reduzido de funcionários nos setores de atendimento ao público e a manutenção aumentando o tempo de resposta aos problemas ocorridos no sistema e o racionamento de água que, naturalmente, já se configura como uma condição desconfortável para o usuário, podem influenciar nos resultados obtidos.

Figura 3 - Distribuição espacial da percepção dos usuários em relação ao serviço de abastecimento oferecido.

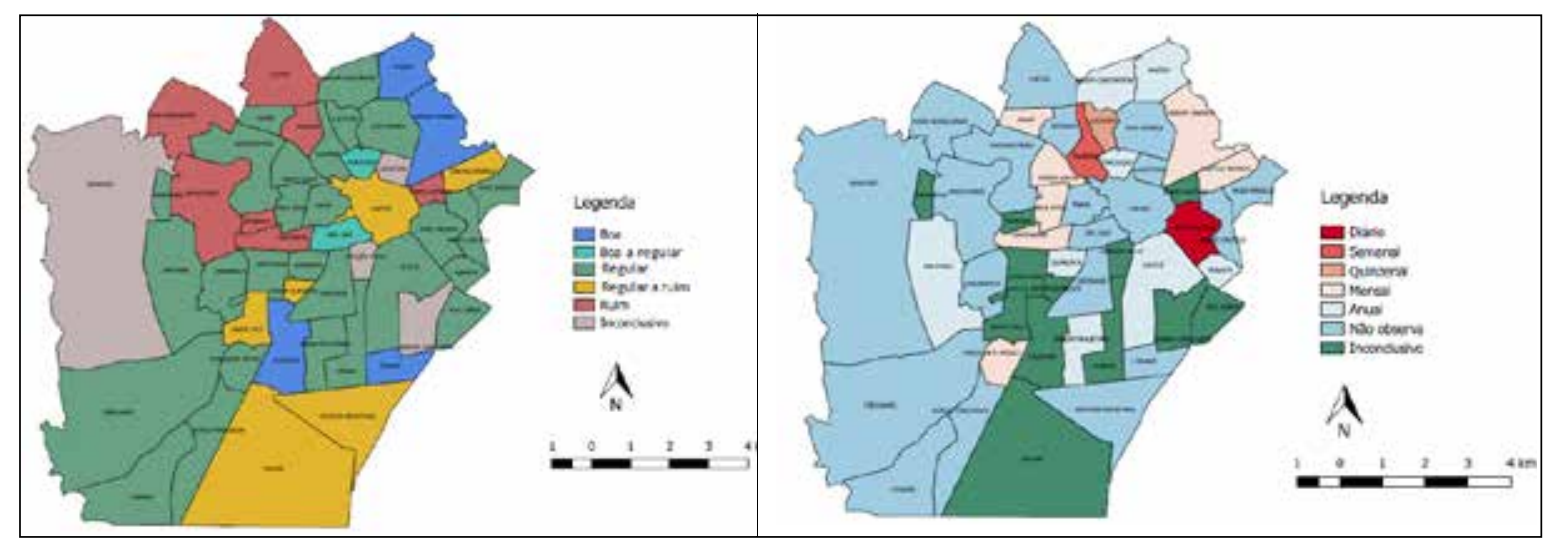

Figura 3a - Qualidade da água oferecida no SAA - Campina Grande.

Figura 3b - Observação de pontos de vazamento na rede de distribuição.

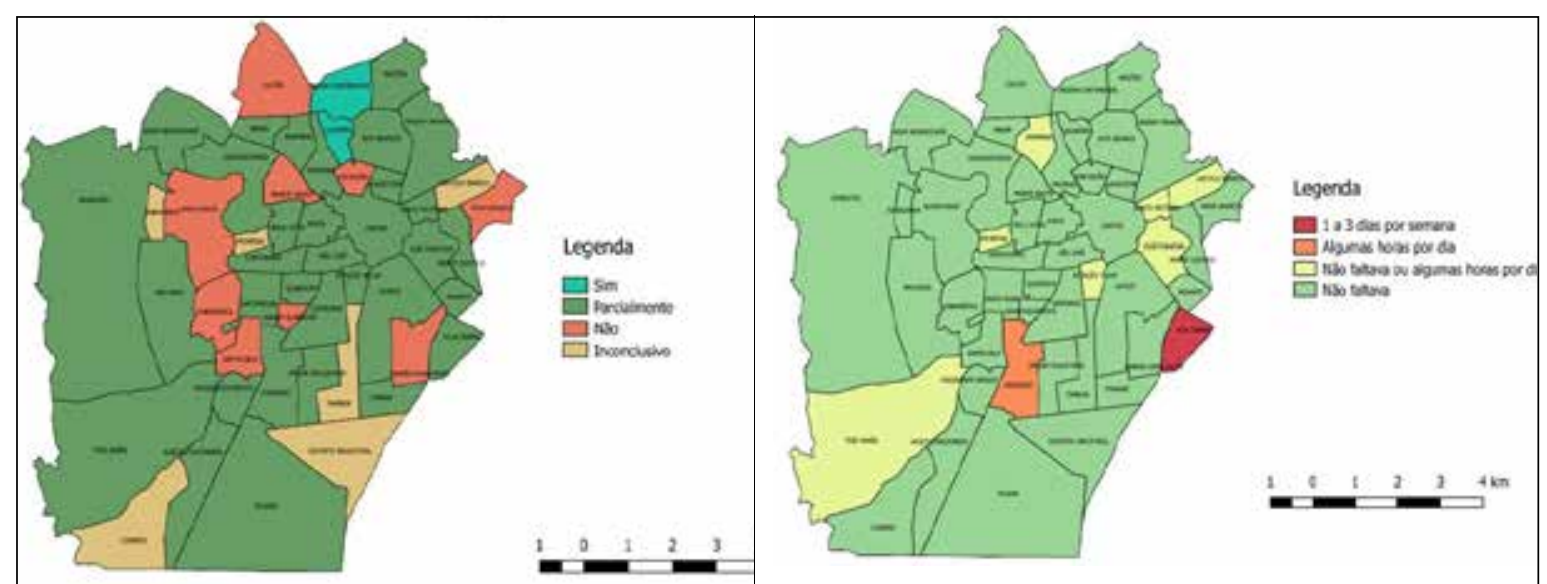

Figura 3c - Eficiência do serviço prestado.

Figura 3d - Intermitência no abastecimento antes do período de racionamento

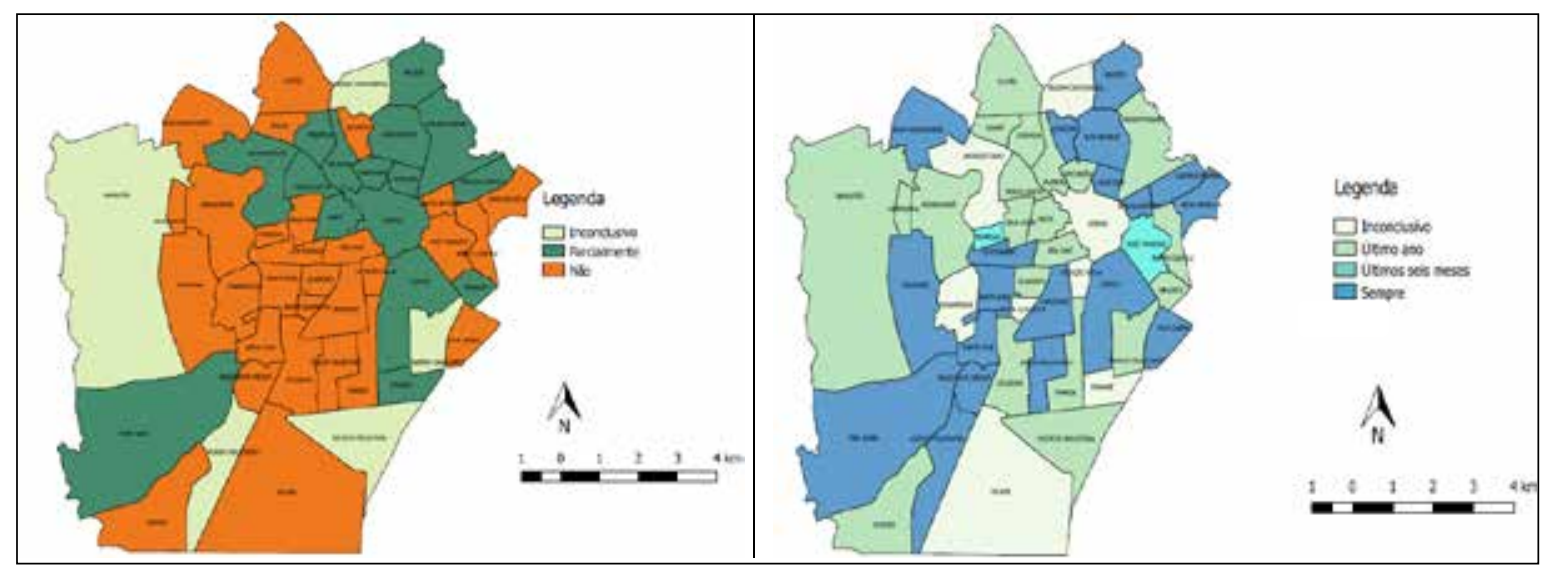

Figura $3 e$ - Satisfação em relação à tarifa paga

Figura 3f - Práticas de economia de água

Fonte: Autoria própria 
A distribuição espacial da intermitência do abastecimento antes do racionamento, descrito na Fig. 3d, mostra que, durante o período normal, não é comum a falta de água na maioria dos bairros. Esse dado mostra que a maioria da população considera de boa qualidade o serviço de atendimento de água oferecido pela concessionária em períodos convencionais. Logo, as manutenções periódicas na rede, com interrupções na distribuição de água, não causam desconforto aos usuários.

Por outro lado, a não percepção de falta de água em períodos de curta duração pode estar associada à presença de reservatórios nas residências dos usuários entrevistados. De acordo com Brito (2016), é comum encontrar em casas dessa região caixas d'água e cisternas para o armazenamento de água.

Quanto ao aspecto econômico (Fig. 3e), a maioria dos entrevistados considera o valor pago pela tarifa de água não condizente com o serviço oferecido. Esse dado reflete que a população espera uma qualidade melhor do serviço prestado pela concessionária uma vez que julga, para o serviço atual, que a taxa cobrada é muito elevada, apesar do $\operatorname{IEF}_{1}$ (Indicador de tarifa média de água) apontar o contrário.

Neste caso, o poder aquisitivo impacta o resultado das respostas, haja vista que em bairros onde os usuários possuem maior renda, a exemplo do Alto Branco e Mirante, foi considerado que o valor pago atende parcialmente às expectativas. Apesar de a opção "Sim" estar disponível no questionário, em nenhum bairro a maioria dos usuários considerou o valor pago completamente adequado para a eficiência com a qual o serviço é prestado.

A CAGEPA possui um sistema de tarifação baseado em faixas de consumo e também uma tarifa social fixa para os usuários de baixa renda. Além disso, o valor pago pela população inclui percen- tuais referentes à coleta de esgoto, que podem chegar a até $100 \%$ em cima do custo cobrado pela água. Este último fator colabora para uma resposta negativa da população neste item.

A análise das respostas dos usuários quanto à economia de água (Fig. 3f) mostrou que a maioria dos entrevistados não se preocupa em economizar água durante os períodos de oferta contínua. Apenas a partir do racionamento, muitos passaram a adquirir práticas de economia de água diariamente. De acordo Chaib et al. (2015), independentemente de períodos de escassez hídrica, é importante que os usuários tenham maior conscientização e pratiquem o uso racional da água, haja vista que se trata de um recurso limitado.

A falta de consciência da população em relação ao uso da água é preocupante, pois a bacia hidrográfica da qual faz parte o reservatório Epitácio Pessoa, que abastece Campina Grande, está inserida em uma região semiárida sujeita a longos períodos de estiagem. Somando-se a este fato, Nunes (2015) ainda alerta que a demanda de água tem sido cada vez maior, nos últimos anos, devido ao aumento populacional registrado na cidade e aos múltiplos usos do reservatório.

\subsection{Resultados obtidos para o IDSA_CG}

$\mathrm{Na}$ Tabela 6 são apresentados os resultados obtidos após a normalização dos indicadores usando a Eq. 3. Quanto mais o valor normalizado se aproximar de 1, melhor é a qualidade daquele indicador para a cidade. Observando a tabela é possível notar que o serviço de abastecimento de água de Campina Grande se destaca principalmente em relação à extensão e cobertura de rede, ao monitoramento e qualidade da água distribuída e perdas de faturamento e hidrometração. Vale ressaltar que, com exceção do indicador de satisfação, os valores dos demais indicadores foram obtidos de bancos de dados oficiais que, muitas 
vezes, são alimentados pelas próprias concessionárias que prestam o serviço. Assim, os resultados da normalização obtidos para os indicadores de qualidade de água, por exemplo, são diver- gentes da opinião da população, como já discutido anteriormente, o que reforça a importância de inserção de um indicador de satisfação do usuário na composição do índice.

Tabela 6 - Resultados obtidos para a normalização e ponderação dos indicadores selecionados.

\begin{tabular}{|c|c|c|}
\hline INDICADORES OPERACIONAIS & Normalização & Ponderação \\
\hline $1 \mathrm{O}_{1}$ - Indicador de hidrometração & 0,89 & 8,13 \\
\hline $1 \mathrm{O}_{2}$ - Indicador de consumo médio de água & 0,55 & 8,13 \\
\hline $1 \mathrm{O}_{3}-$ Indicador de consumo de energia & 0,35 & 8,75 \\
\hline $1 \mathrm{O}_{4}$ - Indicador de perdas na distribuição & 0,04 & 7,50 \\
\hline $1 \mathrm{O}_{5}$ - Indicador de macromedição & 0,57 & 9,13 \\
\hline INDICADORES ECONÔMICO-FINANCEIROS & Normalização & Ponderação \\
\hline $\mathrm{IEF}_{1}$ - Indicador de tarifa média de água & 0,04 & 8,38 \\
\hline $\mathrm{IEF}_{2}$ - Indicador de desempenho financeiro & $-0,01$ & 9,00 \\
\hline $\mathrm{IEF}_{3}$ - Indicador de despesa de exploração por $\mathrm{m}^{3}$ faturado & 0,45 & 7,50 \\
\hline $\mathrm{IEF}_{4}$ - Indicador de evasão de receitas & $-0,41$ & 7,38 \\
\hline $\mathrm{IEF}_{5}$ - Indicador de perdas de faturamento & 1,00 & 6,75 \\
\hline $\mathrm{IEF}_{6}$ - Indicador de despesas com energia elétrica & 0,35 & 9,25 \\
\hline INDICADORES DE QUUALIDADE & Normalização & Ponderação \\
\hline IQ_- Indicador de Incidência das análises de cloro residual livre fora do padrão & 0,94 & 9,00 \\
\hline $\mathrm{IQ}_{2}$ - Indicador de Incidência das análises de turbidez fora do padrão & 0,95 & 8,25 \\
\hline $\mathrm{IQ}_{3}$ - Indicador de Incidência das análises de coliformes totais fora do padrão & 0,98 & 8,00 \\
\hline $\mathrm{IQ}_{4}$ - Indicador de conformidade da quantidade de amostras - Cloro residual livre & 1,00 & 8,25 \\
\hline $\mathrm{IQ}_{5}$ - Indicador de conformidade da quantidade de amostras - turbidez & 1,00 & 7,63 \\
\hline $\mathrm{IQ}_{6}$ - Indicador de conformidade da quantidade de amostras - coliformes totais & 1,00 & 7,88 \\
\hline INDICADORES INFRAESTRUTURA & Normalização & Ponderação \\
\hline $\mathrm{IE}_{1}$ - Indicador de extensão da rede & 0,94 & 8,25 \\
\hline $\mathrm{IE}_{2}$ - Indicador de cobertura da rede & 1,00 & 9,00 \\
\hline INDICADORES DE RECURSOS HUMANOS & Normalização & Ponderação \\
\hline $\mathrm{IRH}_{1}$ - Indicador de resposta às reclamações & 0,76 & 8,63 \\
\hline $\mathrm{IRH}_{2}$ - Indicador de produtividade pessoal total & $-0,01$ & 7,63 \\
\hline $\mathrm{IRH}_{3}$ - Indicador de satisfação & 0,45 & 8,57 \\
\hline
\end{tabular}

Fonte: Autoria própria

Os resultados encontrados após a ponderação dos indicadores utilizando os critérios estabelecidos na Tabela 3 também estão indicados na Tabela 6. Os especialistas levaram em consideração as deficiências já conhecidas no serviço de abastecimento de água de Campina Grande, assim como também os problemas vivenciados com o extenso período de escassez hídrica e os riscos eminentes de desabastecimento. Os maiores pesos foram atribuídos aos indicadores de macromedição $\left(\mathrm{IO}_{5}\right)$, desempenho financeiro $\left(\mathrm{IEF}_{2}\right)$, despesas com energia elétrica $\left(\mathrm{IEF}_{6}\right)$, cobertura de rede $\left(\mathrm{IE}_{2}\right)$ e Incidência das análises de cloro fora do padrão (IQ $)$.
A agregação dos indicadores foi feita conforme indicado na Eq. 4 e levando em consideração os valores obtidos nas etapas de normalização e ponderação. $O$ valor encontrado para o IDSA-CG foi de 4,81 - permitindo a classificação do serviço dentro da categoria REGULAR. Esse resultado indica que, apesar de alguns indicadores isolados apresentarem resultados dentro do esperado, quando avaliado o conjunto, no qual são levados em consideração também outros indicadores com respostas menos satisfatórias, o índice geral diminui, mostrando mais claramente a visão global do serviço. 
O resultado REGULAR para o IDSA-CG parece apresentar coerência com a opinião pública obtida nas entrevistas. No entanto, é importante destacar que essa classificação teve como base a avaliação dos indicadores propostos para a pesquisa. Caso indicadores sejam incorporados ao índice, a classificação final poderá ser alterada. Apesar das restrições encontradas, principalmente no tocante à obtenção de dados, que limitaram a escolha dos indicadores para construção do IDSA-CG, entende-se que o conjunto de informações utilizadas na pesquisa é satisfatório para subsidiar a tomada de decisão por parte dos órgãos gestores e contribuir para a criação de medidas administrativas e estruturantes que visem à melhoria do serviço oferecido a população.

\section{CONCLUSÃO}

Concluiu-se que a partir da avaliação individual de indicadores foi possível retratar com mais clareza os principais problemas associados ao serviço de abastecimento de água e auxiliar a busca de melhoria contínua, além de fomentar o correto direcionamento dos recursos pela concessionária visando a excelência do serviço. Pelo somatório dos indicadores avaliados, obteve-se a classificação REGULAR para o IDSA-CG. Esse resultado poderá contribuir para a melhoria da gestão do serviço de abastecimento de água. $O$ indicador de satisfação foi imprescindível para o desenvolvimento de um índice com maior representatividade, pois agregou aos dados técnicos a opinião do receptor final. Sugere-se a continuidade dos estudos nesta linha, de forma a agregar novos indicadores para a composição do IDSA-CG tornando-o ainda mais próximo da realidade vivenciada pela população e pela concessionária responsável pelo serviço oferecido.

\section{CONTRIBUIÇÃO DOS AUTORES}

Todos os autores contribuíram de forma igualitária.

\section{REFERÊNCIAS}

ABAR. Saneamento básico: Regulação 2007. Fortaleza: Pouchain Ramos, 2008.

BRITO, C. dos. S. Crise hídrica e impactos sobre o abastecimento doméstico na cidade de Remígio - PB. 2016. 34p. Monografia (Licenciatura em Geografia).Universidade Estadual da Paraíba. 2016.

BORGES, E. J. B. Análise da micromedição do volume de água potável domiciliar e sua influência no cálculo do volume de perdas no sistema de distribuição. 2007. 88f. Dissertação (Mestrado em Engenharia Civil). Universidade Federal de Uberlândia, 2007.

BRASIL. Ministério da Saúde. Portaria de Consolidação $\mathbf{n}^{\circ}$ 5, de 28 de setembro de 2017. Consolidação das normas sobre as ações e os serviços de saúde do Sistema Único de Saúde. Diário Oficial da União, Brasília, 2017.

CARVALHO, P. S. O. de. Controle para bombeamento distribuído com vistas a minimização dos custos energéticos aplicado a sistemas de abastecimento de água. 2012. 150f. Tese (Doutorado em Engenharia Mecânica). Universidade Federal da Paraíba, 2012.

CHAIB, C. K. B.; RODRIGUES, F. C.; MAIA, B. H.; NASCIMENTO, N. de. $O$. Avaliação do potencial de redução do consumo de água potável por meio da implantação de sistemas de aproveitamento de água de chuva em edificações unifamiliares. Revista Brasileira de Recursos hídricos - RBRH . Vol. 20 n³. Porto Alegre. jul./set. 2015 p. $605-614$.

COSTA, S. A. B.; CORTÊS, L. S.; NETTO, T. C.; FREITAS JR, M. M. Indicadores em saneamento: Avaliação da prestação dos serviços de água e de esgoto em Minas Gerais. Revista UFMG, Belo Horizonte, v. 20, n.2, p. 334-357, Jul/Dez de 2013.

GALVÃO JÚNIOR. A. C. Desafios para a universalização dos serviços de água e esgoto no Brasil. Revista Panamericana de Salud Publica. 2009;25(6):548-56.

GONÇALVES, K. O; FERNANDES, L. L.; GIRARD, L. Diagnóstico do serviço de abastecimento de água na percepção do usuário no município de Barcarena-Pará. Monografias Ambientais, v. 14, n. 1, 2015.

HELLER, P. G. B.; NASCIMENTO, N. O.; HELLER, L.; MINGOTI, S. A. Desempenho dos diferentes modelos institucionais de prestação dos serviços públicos de abastecimento de água: uma avaliação comparativa no conjunto dos municípios brasileiros. Engenharia Sanitária e Ambiental. 17.3, 2012.

INSTITUTO REGULADOR DE ÁGUAS E RESÍDUOS - IRAR. Relatório anual do sector de águas e resíduos de Portugal (2007) - Avaliação da qualidade do serviço prestado. Lisboa, 2008.

JUWANA, I.; MUTTIL, N. e PEREIRA, B. J. C. Indicator-based water sustainability - A review. Science of the Total Environment, v. 438, Set. 2012. 
LOPES, W. S.; RODRIGUES, A. C. L.; FEITOSA, P. H. C.; COURA, M. A.; OLIVEIRA, R.; BARBOSA, D. L. Determinação de índice de desempenho do serviço de esgotamento sanitário em Campina Grande - PB. RBRH, v. 21, n. 1, jan./mar. 2016.

MARINHO, I. M. R. S.; GAMA, N. I. Avaliação do saneamento urbano de Macapá através do índice de qualidade do saneamento ambiental. 2014. 61f. Monografia (Bacharelado em Ciências Ambientais). Universidade Federal do Amapá, Macapá. 2014.

MOURA, G. N.P. de. A Relação Entre Água e Energia: Gestão Energética nos Sistemas de Abastecimento de Água das Companhias de Saneamento Básico do Brasil. 2010. 222f. Dissertação (Mestrado em Ciências em planejamento energético). Universidade Federal do Rio de Janeiro. 2010.

NASCIMENTO, R. S.; RIBEIRO, M. A. F. M.; BARBOSA, D. L.; OLIVEIRA, R.; MEIRA, C. M. B. S.; OLIVEIRA, L. T. F.; LUCENA, D. P. M. M. Análise da percepção sobre a qualidade do sistema de abastecimento de água na cidade de Campina Grande - Paraíba. In: XX SBRH. ABRH. Bento Gonçalves-RS, 2013. Anais...

NUNES, T. H. C. A gestão do reservatório Epitácio Pessoa e regras de operação otimizadas. 2015. 74f. Dissertação (Mestrado em Engenharia Civil e ambiental) Universidade Federal de Campina Grande. 2015.

OGATA, I. S. Desenvolvimento do índice de pobreza hídrica para a bacia hidrográfica do Rio Paraíba. 2015. 104f. Dissertação
(Mestrado em Engenharia Civil e Ambiental). Univerdidade Federal de Campina Grande. 2014.

PAULINS, V.A. An analysis of customer service quality to college students as influenced by customer appearance through dress during the in-store shopping process. Journal Retailing Consumer Service, v. 12, p. 345-355, 2005.

PREFEITURA MUNICIPAL DE CAMPINA GRANDE. Plano Municipal de Saneamento básico - Relatório Síntese. 2015. 138p.

SILVA, J. F.; MEDEIROS, L. E. L.; RODRIGUES, A. C. L. Gestão de perdas em sistemas de abastecimento de água. Estudo de caso: cidade de Campina Grande/PB. IN.: II Simpósio sobre sistemas sustentáveis. 2015. Anais...

SNIS - Sistema Nacional de Informações sobre Saneamento. Diagnóstico de informações sobre saneamento - 2016. Disponível: http://www.snis.gov.br/. Acesso:24 nov. 2016.

TARDELLI FILHO, J. Aspectos relevantes do controle de perdas em sistemas públicos de abastecimento de água. Revista DAE. jan.-abr. p. 06-20. 2016.

TRATA BRASIL Instituto. Ranking de Saneamento, 2017. Disponível em: http://www.tratabrasil.org.br. Acesso em: 20 de fev. 2016.

VON SPERLING, T. L; VON SPERLING, M. Proposição de um sistema de indicadores de desempenho para avaliação da qualidade dos serviços de esgotamento sanitário. Revista de Engenharia Sanitária e Ambiental. v. 18, dez. 2013. 